\title{
A Marking Heuristic for Materials in a Shared Print Agreement
}

\author{
Evan M. Anderson
}

Shared print agreements are increasingly being used to account for space and budgetary constraints. However, there is a dearth of information in both the literature and in the available program documentation regarding quotidian, yet essential, practicalities such as additional physical marking of materials that have been committed to be retained. This paper argues for the necessity of specific program-based marking on the basis of levels of access stipulated by agreements, that traditional rationales for marking are still relevant, and that these rationales are subject to the contexts of specific shared print agreements. Lastly, it proposes a heuristic based on access to guide policy makers.

S pace is at a premium in research libraries. More institutions and their gov$S$ erning bodies look to repurpose footprints once devoted to stacks and to find ways to allow for the maintenance of retrospective physical collections in a time of increasing emphasis on social collaboration and reliance on digital technologies. The lack of space is coupled with tightening budgets, a growing realization of the costs of maintaining print materials in open stacks, and the growing acceptance of digital surrogates (and born-digital resources) across academic disciplines. As such, academic libraries are turning to more cooperative forms of collection management, particularly for large print serial runs but also for low-use monographic collections. There is a growing corpus of literature describing these plans, their ontologies, organizational structures, and primary considerations for institutions considering initiating such projects. However, despite the robust literature and online program documentation available for review and emulation, many practicalities are rarely covered, articulated, or even defined.

One such practicality is the need for additional marking of items identified in a shared print agreement. Minimal information exists on basic benchmarks or best practices or even a minimum standard proposed in the literature, and there is a corresponding lack of recommendations or descriptions in program documentation from many regional and national shared print agreements. This paper advocates for the need to consider marking in shared print agreements and establishes a heuristic to guide decision makers when crafting or amending policies in shared print agreements. Using a systematic analysis of the needs of shared print programs and rationales for marking, this paper demonstrates that traditional marking concerns are still relevant, if not more so, in an era of electronic resources and last-resort copies; it highlights the major considerations for such additional marking, proposes possible explanations to account for the lack of practicalities in both the literature and in project documentation, and poses areas for further consideration and research.
Evan M. Anderson (evananderson1@ gmail.com) is a Collection Development Librarian at Kirkendall Public Library, Ankeny, lowa.

Manuscript submitted February 9, 2016; returned to author for revision April 7 2016; revised manuscript submitted April 15, 2016; accepted for publication July 7, 2016. 
First, the term shared print agreement must be defined and the scope of this paper must be established. Kieft and Payne define a shared print agreement as a

formal program in which multiple libraries coordinate long-term retention of print materials and related services by one or more participants to support preservation and allow space recovery among campus collections. A shared print agreement is not the same as a shared storage facility. Rather, it is characterized by an explicit commitment to retain materials for a specified time period (or indefinitely) in potentially multiple locations by multiple partners . . . also called "print archives" or "shared collection management."

This definition provides the framework for an analysis of practicalities presented in this paper. A shared print agreement includes two or more partners, one or more locations, focuses on print materials and is subject to retention, preservation, and space-saving considerations. Thus the heuristic established for marking such materials incorporates these varied requirements and is, in turn, justified by them.

\section{Literature Review}

This formal review of the literature considers the following: a survey of current articles concerning physical marking of materials in general, a review of articles covering shared print agreements, and an examination of articles in which these subjects converge.

There is no significant body of recent literature on the subject of physical marking from the last two decades (a period that roughly corresponds with the rise of shared print agreements). Spidal provides a general overview of the history of monographic processing and library technical services. She notes that "recent literature has focused primarily on non-monographic formats." She also advances the motivation for physical marking-ownership, circulation requirements, location identification, protection, and security. ${ }^{3}$ Dixon questions whether marking actually defaces an item and provides examples of solutions from others, such as using pencils to write in accession information. ${ }^{4}$ Lieberman concurs that marking may be damaging, but it is "planned disfigurement" and is necessary to help safeguard the item. ${ }^{5}$ General textbooks on technical services are also short on detail and defer primarily to local practices and procedures. Evans, Intner, and Weihs provide a loose set of examples of methods libraries use to mark materials and identify a familiar set of motivations: "evidence of ownership, location information, a way to record and track use." Current articles that delve into the specifics of physical marking tend to focus on the technology used for processing: improvements in label printing and, more recently, barcoding. ${ }^{7}$ Keifer promotes using the integrated library system (ILS) to batch process labels for transferring materials to a high-density storage facility rather than a previous approach of one item at a time. ${ }^{8}$ Given the ubiquity of marking for general collection materials in academic libraries, both as a historical role and present responsibility, it is not surprising that the general subject has not received much recent treatment by academics. In essence, libraries are already experts at processing and have few questions about best practices outside of minor technical improvements.

Many papers concerning shared print agreements provide the general rationales underpinning such projects. Smith states that many users believe that "they know libraries are ... preserving everything that is interesting or useful" (emphasis in original). ${ }^{9}$ However, Smith argues that there are constraints that prevent libraries as single actors to meet this expectation and recommends creating networks of repositories with a variety of preservation and retention obligations. Additionally, Smith notes that libraries must "divorce ownership per se from governance" to collaborate effectively. ${ }^{10}$ Clement extends this issue of ownership and governance to one of utility and trust by arguing that "it would be more useful for libraries to pool their resources than to compete with each other for material."11 He echoes the financial, space, and preservation motivations advanced by Smith. ${ }^{12}$ Lawrence argues for "deep collaboration" in multiple aspects of librarianship including shared print at the University of California (UC) system of libraries to account for these same constraints. ${ }^{13}$ Kieft and Payne argue that libraries need to focus on rare materials and unique items and move their institutions from being " book-centered' to the 'learning-centered' library" and that deeper collaboration is the vehicle for this. ${ }^{14}$ The relationship libraries have with their institutional faculty must also be considered and strong collaboration in shared print agreements offers opportunities to meet the expectations of both new and established faculty. ${ }^{15}$ Thus each of these authors discuss the reasons libraries are working together and provide a general sense of the current directions in shared print agreements.

Others, such as Genoni, attempt to provide an overview of projects underway. Focusing on the attitudes of Australasian university librarians, Genoni concludes that after more than ten years of work and discussion, "there has been occasional agreement, some gains, and a great deal of hesitancy."16 Demas provides an overview of both North American and British projects and highlights some infrastructures that have been established. ${ }^{17} \mathrm{~A}$ review of expanding programs in the last fifteen years demonstrates the variety of models available for shared print, from small regional agreements between pairs of institutions to larger national-scale repositories. ${ }^{18}$ These agreements can have a variety of shared 
governance approaches, shared space allocations, allotments for materials and multiple types of services, and, as Payne recommends, "different service levels to support different needs for different constituencies."19 These repositories can either be light (fully accessible) or dark (closed, for preservation purposes only) with variations, or degrees of dimness, between. ${ }^{20}$ This multiplicity of models-who and how institutions share, what level of access they provide, and what levels of ownership and governance are applied-all need to be addressed with respect to establishing any policies on physical marking. Additionally, the rationales for such cooperative programs must also be accounted for while not ignoring the potential limitations of temporal and financial resources.

The questions these papers raise and the considerations they pose are partially answered in reports by Malpas and Reilly $\mathrm{Jr}^{21}$ These authors discuss the multiple modes of governance and collection building, de-duplication and rationalization, and how ownership and access are handled by a variety of major programs both nationally and internationally; they also advocate for documentation "through contracts, written agreements, bylaws, memoranda of understanding, policies and similar instruments." ${ }^{\text {"22 }}$ Demas and Miller concur: "libraries should take the time to write formal collection management plans in preparation for participating in shared print archiving programs." ${ }^{23}$ These reviews call for documentation of policy and provide some detail on how programs have been constructed and formalized, but much of the essential quotidian tasks, such as physical marking, receive no elaboration.

In discussing specific shared print agreements, more formalized procedures are documented for a few programs. However, these details focus on nonmarking tasks or responsibilities. One such task includes creating accurate holdings information for shared catalogs ${ }^{24}$ Further articles address intellectual completeness verification for JSTOR print backfiles. ${ }^{25}$ The thorny issue of shared ownership is treated through establishing an appropriate legal framework for "an ownership system called tenancy in common . . . all joint owners have an undivided interest in the property in its entirety." ${ }^{\text {26 }}$ De-acidification and other preservation treatments are discussed ${ }^{27}$ Effective interlibrary loan (ILL) is also considered. ${ }^{28}$ However, three projects in the literature discuss marking. For the Orbis Cascade Distributed Print Repository (DPR),

staff from participating libraries will physically identify the DPR volumes by placing a specially designed Alliance bookplate in every volume of each title for which that library is responsible. The bookplate will clearly identify the item as being part of the DPR and also indicate that the volume does not circulate. ${ }^{29}$
For the JSTOR/UC back-files archive project at the Southern Regional Library Facility (SRLF), "processors add item barcodes to each volume.,30 For the Pennsylvania Academic Library Consortium (PALCI) project, "physically stamping volumes to indicate they belong to the archive [was] eliminated altogether," though no explanation was provided by the authors. ${ }^{31}$

The literature therefore leaves a general set of rationales for marking, some minor comments on techniques and technologies, and lays out the broad shape of some shared print agreements. The general marking rationales are summarized and further explored below and support the applicability and necessity of marking in shared print agreements.

\section{Reasons to Mark}

As mentioned above, there are several reasons why libraries have traditionally marked their materials. Materials are only discoverable if they have an identifying mark that allows a patron or staff member to physically locate them. Once an item is off the shelf or out of the owning institution, the markings allow a patron to return it correctly, something that even RFID tags cannot fully guarantee. Marking can be used to assist in preservation and salvage decisions during treatment or an emergency situation. It can help thwart would-be thieves, particularly those seeking relatively clean copies of high-value or rare materials. Lastly, a bookplate mentioning a specific donation, special collection, grant, or other funding source can encourage new donors (or established ones) to contribute. Donor support of the library is clearly and physically demonstrated.

Each of these reasons to mark extends to the materials that are committed to be retained by a library participating in a shared print agreement. Regardless of how the item is disposed, an item must still be discoverable, it must demonstrate its ownership if it is circulated or lent to another institution via ILL, may be subject to disaster recovery and require treatment, or may be threatened with theft-all of these are of increased concern because of institutional commitments. Participants have pledged, often in writing, to protect these materials, and the other members are counting on their long-term survival. Further, as with general collections, increased access increases risk of loss, damage, theft, or misfiling. Therefore the need for consistent, clear, and considered marking is increasing. In libraries of any reasonable size, which includes most institutions that participate or would participate in shared print agreements, marking serves for staff notification as well. For example, staff who are involved in physically de-accessioning materials may not also be the staff who update, suppress, or delete bibliographic or holdings records in the ILS and may not then be aware of retention requirements documented in said records. Clear 


\begin{tabular}{llllllll}
\hline Table 1. Program Documentation Review & & & & & \\
\hline Program & Markings & Cataloging & Shelf Audit & In-House Use & ILL Loan & ILL Copy & Transfer of Ownership \\
UKRR & Unspecified & Yes & Yes & Yes & No & Yes & retained by library \\
PASCAL & Unspecified & Yes & No & Yes-Reading room & Yes & Yes & retained by library \\
WEST & Unspecified & Yes & Volume level & Yes & Yes & Yes & transferred to holding library \\
GWLA Shared Print & Unspecified & Yes & Volume level & Yes & Yes & Yes & retained by library \\
CARM_CAVAL & Unspecified & Yes & Volume level & Yes & Yes & Yes & Ceded to consortium \\
TUG & Unspecified & Yes & Yes & Yes & Yes & Yes & retained by library \\
UC RLF & Barcodes & Yes & Yes & Yes & Yes & Yes & retained by library \\
CIC & Barcodes & Yes & Volume level & unspecified & Yes & Yes & retained by library \\
UI-ISU-UW DPR & Unspecified & Yes & Volume level & Yes & Yes & Yes & transferred to holding library \\
\hline VALE & Unspecified & Yes & No & Yes & Yes & Yes & retained by library \\
CONSTOR & Unspecified & Yes & Yes & unspecified & Yes & Yes & retained by library \\
\hline Orbis Cascade DPR & Bookplate & Yes & Yes & Yes & Yes & Yes & transferred to holding library \\
\hline PALCI & Match holdings & Yes & Issue level & Yes & Yes & Yes & transferred to holding library \\
\hline
\end{tabular}

markings serve as a final safety measure to ensure a library does not accidentally discard an item subject to long-term commitments. Finally, given concerns raised by Neal, good public relations regarding shared print agreements can demonstrate to faculty that the library is wisely expending its resources; even if the library is de-accessioning materials locally, it still can provide access quickly and effectively and can reallocate space or collection maintenance dollars in a more effective manner. ${ }^{32}$

This paper uses the above generalized rationales for marking, plus the ontologies and modalities of shared print agreements demonstrated in the literature to assert the requirements for and necessity of marking items included in a shared print agreement. These rationales and concerns will be further documented and addressed below following a careful consideration of the available project documentation of currently existing shared print programs.

\section{Program Documentation}

This paper adapts the method used in the Research Library Group's Shared Print Policy Review Report to analyze project and program documentation from thirteen regional, national and international shared print programs to help define the guidelines and considerations for marking in a shared print agreement. ${ }^{33}$ This systematic review of available project documentation evaluated the following elements:

1. marking of materials

2. updating, changing, or creating cataloging records
3. condition and intellectual completeness verification

4. in-house and on-site usage

5. ILL (both using digital surrogates and physical loans)

6. transfers of ownership

Only projects with online documentation available were considered. Many other projects were rejected as the program materials were online but restricted. See appendix A for more information on the thirteen projects that were reviewed. This review allows for some applicable generalizations because of the number of programs considered and their relative uniformity. See table 1 for a consolidation of the project review.

As noted in the literature review, requirements for physical marking were largely absent in program documentation. Of the thirteen projects, only four (31 percent) contained any documented requirements. Two of these projects (15 percent) stipulated that barcodes would need to be placed for the purposes of access. Both of these projects are for repositories (University of California Regional Library Facilities and the Committee on Institutional Cooperation (CIC) repository at Indiana University). As discussed in the literature, a bookplate is required for the DPR. Further, the PALCI project requires that if there is a transfer of holdings, the new library must eradicate original markings and remark the materials to comport with local practices, but not employ any specific agreement-designated mark.

Not surprisingly, all thirteen projects (100 percent) require some additional cataloging work, whether it is updating holdings statements or adding an OCLC symbol for ease of consortial access or creating a union catalog. For purposes of discovery, bibliographic records or up-to-date 
holdings statements are absolutely essential. This requirement speaks to the nature in which these shared print agreements will be used: multiple libraries will need to be able to review each other's records to de-duplicate and rationalize holdings and to locate original print materials when digital surrogates are insufficient for patron use. Since much work will be done comparing holdings at a distance rather than by reviewing each physical site (particularly for both distributed and repository models), accurate and up-to-date catalogs are necessary.

A majority of the agreements ( 85 percent) specify some form of shelf audit must be completed. Most of these, if the level is specified, are at the volume level. Only one specifies to the issue level. Many the agreements (38 percent) only stipulate that some form of review for completeness and condition be undertaken. As with cataloging, a verification of intellectual completeness and evaluation of condition is absolutely essential, as de-duplication would need to focus on best available copies and any long-term commitments would focus on complete serial runs or intact and stable monographs. The willingness of program developers to require this level of intensive labor implies the level of value these projects have and can be inferred to indicate why a program should undertake additional onerous tasks to preserve the integrity of collections. This core idea is elaborated below.

Components of these shared print agreements also cover multiple forms of access. All thirteen projects (100 percent) guarantee access through digital surrogates (ILL scanning/copying) either for members or any other requesting institution. The majority of programs (92 percent) also allow ILL of physical volumes. A large number (85 percent) also allow in-house or on-site usage. This on-site usage may either be in a reading room made available to researchers visiting the housing repository or the local holding library in the case of distributed models. This high level of access (both by patrons and staff) must be considered when determining what extent of physical markings are necessary. Access increases risks to individual items, increases risks to intellectual completeness, and poses other long-term preservation threats, particularly if items in a shared print agreement are last-resort copies.

Ownership is the last element evaluated in this review. Generally, an owning institution will have its own set of markings subject to local practices, requirements, and institutional history. In many shared print agreements, holdings are either deposited in a shared repository, transferred to another library to fill in gaps in serial runs, or retained on the shelf as part of a distributed model. If ownership is transferred, then markings would need to be updated as mentioned above with the PALCI project. If ownership is maintained, even if items are deposited at an off-site location, original markings are likely still needed but additional markings, such as barcodes for locations would be required. Four out of thirteen (31 percent) of these agreements specify that ownership is transferred to the new holding institution. One (8 percent) specifies that ownership is ceded to the consortium. In both these cases, new markings would be necessary. The majority (61 percent) indicate that ownership is maintained by the original library that purchased the items governed under the agreement. This does not mean that no further marking is required, only that at least some of the original marks must be maintained in case the agreement is terminated or items are recalled.

By evaluating the practicalities of these agreements, it becomes apparent that access is the primary determinant for additional marking. Even ownership is subordinate because materials must be discoverable, able to be reshelved, and returnable. Thus access is the concern that necessitates specification of additional marking in shared print agreements and serves as the basis for the heuristic proposed below. Before access can be used as the primary criterion, the considerations and complexities teased out by the review of program documentation need to be explored.

\section{Considerations for Marking}

Even with strong incentives to mark each volume included in a shared print agreement, many additional factors should be considered when determining what kind of mark and to what extent marking ought to be undertaken. Access is a guidepost, but access does not exist in a vacuum. Factors include the following:

- who owns the materials

- the item location

- who has access

- the timeframe of the commitment

- the scope of the project

- what staff are available

Ownership will dramatically govern the type of marking a library can or will undertake. In a distributed model, in which several institutions hold journal runs, ownership will be diverse and the markings already present on any particular volume will convey ownership. As Maes and ThompsonPrzylucki indicate, there are often issues regarding transfer of materials purchased using state funds. ${ }^{34}$ Different programs have used methods of dealing with this limitation, such as extended and indefinite loans. Therefore, if materials are exchanged, lent, or given (depending on applicable laws), the receiving institution will need to re-mark the materials to comport with its own local practices, particularly if they will be shelved on open stacks. With single-location repository models, ownership may either be transferred to the holding 
institution or a governing consortium. In either instance, as demonstrated by the barcoding at the SRLF, some basic marking is undertaken and is absolutely necessary. ${ }^{35}$ Yet the need to demonstrate ownership is subordinate to the need to provide access. Ownership proof is largely irrelevant if an item cannot be discovered or reshelved properly.

Location of the item also affects the nature of any additional marking. If the item is being removed to a remote location, it would be subject to additional marking as discussed above. When the model of the shared print agreement is distributed, additional markings might not be necessary to provide access. However, as discussed above, the more accessible an item is, the more important the other rationales for marking become. The greater the access, the greater the possibility of theft, misplacement, use by patrons who do not know where the item goes, and a greater likelihood of accidents or emergencies involving fire, water, or food.

The location is virtually inseparable from the issue of who is given access. If the shared print agreement specifies a dark archive-i.e., the collections are only open to those involved in the processing and maintenance of the item-only a new barcode or accession number is necessary. If the agreement is for dim archives, light archives, or ILL services (physical loan rather than digital surrogates) and circulation services are allowed, then the need for marking becomes greater still. Additionally, as access is expanded, the benefits of positive public relations from marking using explanatory bookplates increases: "Faculty reactions to the impact of removal of materials from campus shelves are normally directed to the library . . . the merging of holdings into shared collections can have a negative effect on a library's standing among its peers." 36 Shared print markings can help ameliorate this negative effect by being a signal for all the other materials that are still accessible through the agreement.

The duration of the commitment also has consequences. If the retention period is extensive, one may want to take an approach more akin to how special collections libraries mark their materials. Forecasting the future, print copies will be less in demand and "service copy collections are virtually becoming dark archives." 37 Long-term commitments will become archival commitments, and what are seemingly common print titles today will become the rare books of tomorrow, perhaps to such a degree that the value of the material as a physical object worthy of study may reach or exceed the intellectual value of its content in the eyes of some researchers. This raises the specter of Lieberman's "planned disfigurement" noted above. ${ }^{38}$ The original (and often heavy) processing on bound serials may someday be artifacts themselves of library practices from earlier periods, but additional markings or re-markings may muddy such future academic analyses. If the retention is for last-copy only, this further increases the complexity of deciding how best to mark the volumes, as these volumes may replace or restore insufficient, damaged, or lost digital surrogates.

The last two listed factors ground any decisions for marking in the reality of the library. When the project is large, with many journal titles and volume runs to be processed again, there will be less incentive to take the time to mark each volume. If staffing resources are not available, then even when the motivations and incentives are clear and present, the work simply will either not get completed or completed in a realistic timeframe. Yet onerous tasks are already undertaken in shared print agreements. As part of the JSTOR/UC shared print project at the SRLF, student workers "undertake an intense validation process to make certain the volume is complete, similarly paginated . . . and in appropriate physical condition," and the CIC working group recommends condition and intellectual completeness of journals "should be carried out at 'the issue level,' meaning an inspection of 'a physical volume looking for obvious missing issues, and review the spine label (volume, issue, and date statements) for accuracy." 39 If libraries value these projects and the shared collections to the degree that they can take the time and resources to do this level of work, they should be able to find the time and resources to provide at least some marking. The marking will help maintain the condition and completeness of these shared collections, all of which these laborious tasks are designed to ensure.

\section{A Heuristic for Marking Materials}

As demonstrated by both the review of project documentation and the literature, there are a multitude of factors that govern both the rationales for marking and the nature of the mark used at any particular institution. Given this variety of considerations, the diversity of shared print agreements and local practices for physical processing, one standardized type of marking (e.g., a book plate, a spine label, a colored dot or tape, a penciled number) cannot be proposed and be useful. A universally applicable system or scheme is simply not a practical, implementable possibility.

However, circulation, ILL services, and general access are consistently shown in both the project requirements and literature to be usually granted or required to some degree. Therefore access becomes the primary criterion governing the necessity for specific marking for the shared print agreement. Access is the single commonality between all shared print agreements, thus it becomes the initial driving point of any decision about marking specifics. The more open and accessible a collection is, the greater the need for an additional mark on each item that is being retained as part of a shared print agreement. As access increases, so too does the need for a specific shared print agreement mark. See figure 1 for a representation of this relationship. 


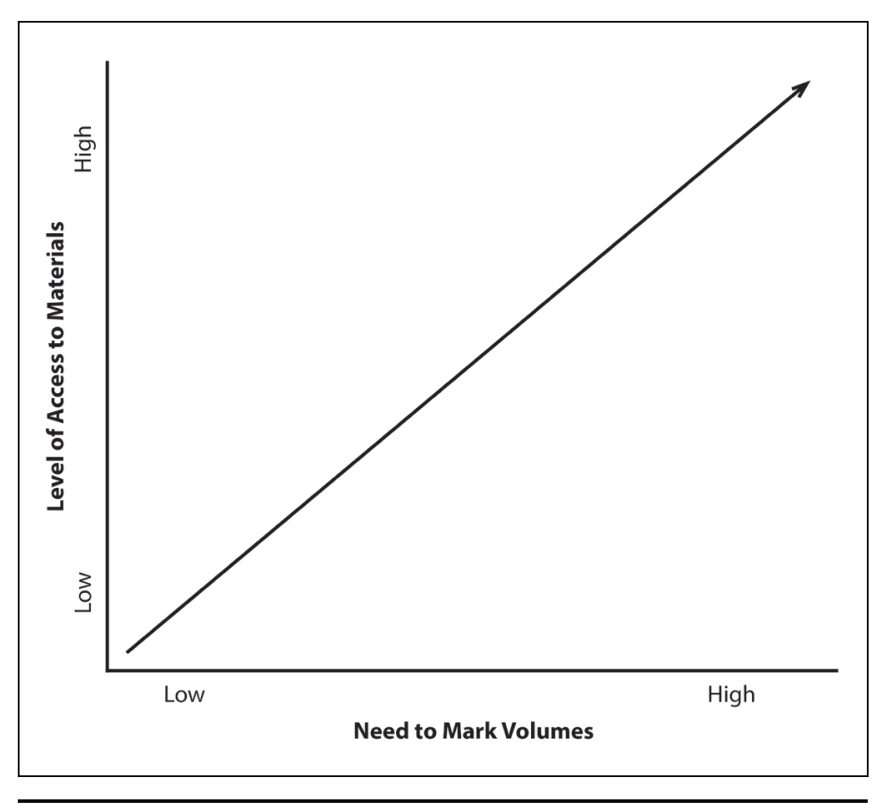

Figure 1. A marking heuristic

Modes of ownership, methods of distribution, preservation programs, and storage arrangements all create bewildering complexities, but access is simple and straightforward. Each institution and consortium will have its own technical services legacy, its own facilities issues, its own public relations concerns; each will have its own, unique context. Conceptually, shared print agreements are broad, therefore any useful tool must be broad. The heuristic is just that - a broadly defined relationship. It is not a complex matrix of analyses but instead a simple tool to cut through all the complexities and allow for decision making. It is not meant to function algorithmically, it is designed to enable decision makers to focus on the most pressing concern of daily operations for an established shared print agreement: access. Access is a standard sliding metric. Can anyone borrow an item controlled by the shared print agreement? Is the item located in open stacks? Can the item be copied or loaned? The heuristic gives decision makers a starting point. If there is little or no access, then other concerns-e.g., discovery and loss-prevention-become almost irrelevant beyond the normal collection management perspective. But, generally speaking, the more users or staff who handle each item, the more it may be used in-house or discharged either to local patrons or to those at other institutions, the more all these issues become increasingly important, driving the need to mark.

Ideally, each institution and consortium undertaking a shared print agreement should mark the materials they have committed to retain because they have invested significant resources acquiring and providing access through technical services processing, building shared collections, rationalizing and de-duplicating, checking for condition and intellectual completeness, preserving, and warehousing these items. The nature of the specific type of marking is subject to the context of the libraries, the types of agreements, the volume of the project, the availability of staffing, and service. Policy makers will have to establish the specifics of the marking to comport with the general reasons for marking. And they will need to do so in accordance with the program considerations for each of the institutions involved. At a minimum, policy makers should explore this issue further and document their decision making. If the goal is to preserve the scholarly record and provide long-term access, not just to free space or to warehouse print resources to avoid discarding them, then these resources must be marked as they always have been: to guide users to them, to collocate them, and to preserve and protect them. Institutions are expending considerable time and funds maintaining these items, so further modest expenses to achieve these goals are fully justified. This heuristic can help prompt these necessary discussions, justify such additional expenditures, and help safeguard the scholarly record.

\section{Future Research}

Shared print agreements have been in place for roughly two decades, and projects are reaching maturity. However, both the literature and the program documentation are often scarce on the practicalities of running such programs. Much material examines the organizational structure, funding, governance of the projects, and documentation on cataloging and holdings statement requirements, but that is roughly the extent. And there are many possible reasons why something such as marking is not actively discussed: Marking is such a common task that libraries assume any necessary marking is being completed (programs that mention barcoding or other technical services may imply this possibility). Many project planners and working groups may deem marking as an unnecessary library practice to be incorporated to any shared print agreement and that the general motivations for marking materials do not extend to shared collections. Marking also may be considered too laborious to be worthwhile; even though there are valid motivations to mark, they are trumped by finite material and temporal resources. Certainly, the lack of discussion may be a confluence of any or all of these factors.

Additional research is needed to fully understand the daily workflows and procedures involved in shared print agreements. Further, research is needed to see who is involved in these procedures, how they are structured organizationally (to whom they report, in which departments they work, whether they are student workers, support staff, 
professionals, or a mix), and how much time they commit to such projects. Concrete data on labor and structure for quotidian operations will allow better evaluations for returnon-investment assessments and to either support or refute the arguments in this paper.

Additional research is needed in the areas of access, loss prevention, usage, and cost utility for shared print agreements. How frequently are committed items used and by whom? Are disaster plans being updated to include specific sections on committed materials? That space and cost savings are accrued in shared print agreements is all but a given, and some initial costing exists to sustain that belief, but more evaluation and more data are necessary. ${ }^{40}$ Gauging the value of agreements for last-resort copies or dark archives that are limited to emergencies only will be difficult.

Ultimately, we need to know more about the benefits and costs of these projects to develop further best practices and to establish that libraries are serving their patrons in the best way possible and being good stewards of both the scholarly record and the finances afforded them.

\section{Conclusion}

Collaborative collections and facilities are being built. Catalogs are being updated and holdings records are being disseminated. Access is provided both physically and digitally. The scholarly record is hopefully being preserved. Shared print agreements are helping drive twenty-firstcentury library practices. But these agreements also need to incorporate the tried and true practices of the past that are underpinned by decades of experience and rationales that still apply. As long as the physical object is a manifestation of the scholarly notification system, it will be subject to the needs of access, ownership, preservation, emergency planning, protection against loss, and public relations. This basic idea and the core principle that with increased access comes with an increased need to mark are easy to articulate, but they are challenging to implement and are subject to all the complexities and constraints that affect research libraries.

\section{References}

1. Robert H. Kieft and Lizanne Payne, "Collective Collection, Collective Action," Collection Management 37, no. 3-4 (2012): 137-52.

2. Debra F. Spidal, "Physical Process of Monographs by Library Technical Services," Library Collections, Acquisitions \& Technical Services 35, no. 1 (2011): 1-9.

3. Ibid., 8 .

4. Jeanette Dixon, “Ask ARLIS I: Museum Library Special Collections: Continuing Education, Marking Guidelines, and
Working with Print Collections," Art Documentation 13 (1994): 64.

5. Ronald Lieberman, "Are Rubber Stamps Better than Chains? Security Concerns and the Marking of Books," College d Undergraduate Libraries 6, no. 1 (1999): 77-80.

6. G. Edward Evans, Sheila S, Intner, and Jean Weihs, Introduction to Technical Services, 8th ed. (Santa Barbara, CA: Libraries Unlimited, 2011).

7. Emily Badertscher, "Yellow Bricks: Combination Lettering on Label Sets Using PASSPORT," OCLC Micro 8, no. 6 (1992): 29-30, 34; Kathy Fladland, "Using CAT ME Plus' Label Module with SE-LIN Labels," OCLC Micro 7, no. 4 (1991): 29-34; Susan Bahrenfuse, "Single Spine Label Production Using WordPerfect," OCLC Micro 6, no. 2 (1990): 6-9; Cheryl D. Walters, "Thermal-Transfer Printing: A Better Way to Print Library Labels," Information Technology \& Libraries 23, no. 1 (2004): 30-36.

8. David Keifer, "Batch Processing Items in a High-Density Shelving Facility," Journal of Interlibrary Loan, Document Delivery \& Electronic Reserve 19, no. 3 (2009): 247-55.

9. Abby Smith, "Common Cause: Taking Care of Print Collections," Library Collections, Acquisitions \& Technical Services 28, no. 1 (2004): 8-12.

10. Ibid., 10.

11. Susanne K. Clement, "From Collaborative Purchasing Towards Collaborative Discarding: The Evolution of the Shared Print Repository," Collection Management 37, no. 3-4 (2012), 153-67.

12. Smith, "Common Cause."

13. Gary S. Lawrence, "Radical Change by Traditional Means: Deep Resource Sharing by the University of California Libraries," Serials 17, no. 2 (2004): 119-25.

14. Kieft and Payne, "Collective Collection," 141.

15. James G. Neal, "Advancing from Kumbaya to Radical Collaboration: Redefining the Future Research Library," Journal of Library Administration 51, no. 1 (2010): 66-76.

16. Paul Genoni, "Storage of Legacy Print Collections: The View of Australasian University Libraries," Collection Management 37, no. 1 (2012): 23-46.

17. Sam Demas, "Curating Collective Collections: Shared Print Collections Reaching Maturity," Against the Grain 24, no. 6 (2012-13): 81-82.

18. Paul Genoni, "An International Review of the Development and Implementation of Shared Print Storage," Australian Academic \& Research Libraries 44, no. 1 (2013): 50-66.

19. Lizanne Payne, "Depositories and Repositories: Changing Models of Library Storage in the USA," Library Management 26, no. 1-2 (2005): 10-17.

20. Mary Jo Zeter, Jeanne Drewes, and Michael A. Arthur, "Paving the Way for Print Repositories through Electronic Access," Serials Librarian 46, no. 3-4 (2004): 263-67.

21. Constance Malpas, Shared Print Policy Review Report (Dublin, OH: OCLC Research, 2009); Bernard F. Reilly Jr. 
Developing Print Repositories: Models for Shared Preservation and Access (Washington, DC: Council on Library and Information Resources, 2003).

22. Reilly Jr., Developing Print Repositories, 36.

23. Sam Demas and Mary E. Miller, "Rethinking Collection Management Plans: Shaping Collective Collections for the 21st Century," Collection Management 37, no. 3-4 (2012): 168-87.

24. Gwen Bird and Gohar Ashoughian, "All Together Now: Planning for Shared Print Archiving at Canada’s Western Universities," Collection Management 37, no. 3-4 (2012): 260-70.

25. Ben Walker, Dan Schoonover, and Raimonda Margjoni, "Creating a Statewide JSTOR Repository: Initial Steps Taken by the Florida State University System," Journal of Interlibrary Loan, Document Delivery \& Electronic Reserve 20, no. 3 (2010): 159-72; Mark Sandler et al., "CIC Co-investment to Protect Print Research Library Collections in the Midwestern United States," Collection Management 37, no. 3-4 (2012): 237-59.

26. Margaret K. Maes and Tracy L. Thompson-Przylucki, "Collaborative Stewardship: Building a Shared, Central Collection of Print Legal Materials," Collection Management 37, no. 3-4 (2012): 294-306.

27. Barbara DesRosiers, Melissa Trevvett, and Michael A. Arthur, "Developing a Distributed Print Depository System," Serials Librarian 48, no. 3-4 (2005): 343-48.
28. Pentti Vattulainen, "Maintaining Access to Print Materials-A Finnish Model," Liber Quarterly 15, no. 3-4 (2005): 310-19.

29. Linda T. Di Biase and Mark R. Watson, "Orbis Cascade Alliance Distributed Print Repository: Organizing Collections at the Consortial Level," Collection Management 34, no. 1 (2008): 19-30.

30. Colleen Carlton et al., "The UC/JSTOR Paper Repository," Serials Librarian 52, no. 1-2 (2007): 135-50.

31. Sharon Wiles-Young, Christy Roysdon, and John Barnett, "No Substantial Penalty for Withdrawal: The PALCI Shared Print Journal Archive," Serials Librarian 62, no. 1-4 (2012): 79-86.

32. Neal, "Advancing from Kumbaya to Radical Collaboration," 73.

33. Malpas, Shared Print Policy Review Report.

34. Maes and Thompson-Przylucki, "Collaborative Stewardship," 302-3.

35. Carlton et al., "The UC/JSTOR Paper Repository," 141.

36. Reilly Jr., Developing Print Repositories, 39.

37. Kieft and Payne, "Collective Collection," 139.

38. Lieberman, "Are Rubber Stamps Better than Chains?," 78.

39. Carlton et al., "The UC/JSTOR Paper Repository," 144; Sandler et al., "CIC Co-investment," 253.

40. Paul N. Courant and Matthew Nielsen, The Idea of Order: Transforming Research Collections for 21st Century Scholarship (Washington, DC: Council on Library and Information Resources, 2010). 